\title{
Arsenic intake from drinking water and food, leading to arsenicosis and malnutrition in Nepal
}

\author{
B. Summers and S. Khokhar \\ School of Food Science and Nutrition, University of Leeds, Leeds, LS2 9JT, UK
}

Poor nutritional status and chronic arsenic toxicity have been reported in Nepal. It is estimated that 2.3 million Nepalese are consuming water with high concentrations of arsenic. In the district of Nawalparasi, $21.1 \%$ of water sources exceed the WHO threshold of $10 \mu \mathrm{g} / \mathrm{l}^{(1)}$.

One of the major aims of the present study was to measure the arsenic intake from water and food within the population and to investigate whether the risk of chronic arsenic toxicity was higher as a result of compounding factors related to nutritional status. Data collection was made between June and August 2008 following registration with local authorities in the district headquarters and after obtaining informed consent from each of the 103 male subjects.

Drinking water was analysed for total arsenic concentration by hydride generation-atomic absorption spectrophotometry at the Environment and Public Health Organization, Kathmandu and individual water consumption recorded over a $24 \mathrm{~h}$ time period. Arsenic intakes resulting from contaminated groundwater were then calculated over a 5-year time period for each subject (age range 25-78 (average 47) years). Subjects were examined for clinical signs of arsenicosis using standard signs. Additional arsenic intake from the diet was calculated from quantified FFQ data and analysis of arsenic concentration in dominant local foodstuffs. BMI, mid-upper arm circumference and calf circumference were recorded by standard methods along with indicators of socio-economic status.

Water arsenic concentration averaged $181 \mu \mathrm{g} / \mathrm{l}$, with highest values of $740 \mu \mathrm{g} / \mathrm{l}$. Arsenic intake from water ranged from 0 to 84.4 (average 11.2) $\mu \mathrm{g} / \mathrm{kg}$ body mass (BM) per d. Compared with the WHO tolerable threshold for arsenic of $2.1 \mu \mathrm{g} / \mathrm{kg} \mathrm{BM} \mathrm{per} \mathrm{d}^{(2)}, 69 \%$ of subjects consumed toxic levels of arsenic from drinking water alone (range $2.2-84.4 \mu \mathrm{g} / \mathrm{kg}$ BM per d), although only $23 \%$ of subjects exhibited clinical signs of toxicity. Clinical toxicity was significantly associated with higher arsenic intake from drinking water $(P<0.001$, df 80 ). The dietary survey revealed the arsenic intake from only four staple foodstuffs averaged $3 \mu \mathrm{g} / \mathrm{kg}$ BM per d. Further investigation revealed that where contaminated water $(500 \mu \mathrm{g}$ arsenic/l) was used in food preparation, mean arsenic intake increased to $20 \mu \mathrm{g} / \mathrm{kg} \mathrm{BM}$ per d (tolerable threshold $<2.1 \mu \mathrm{g} / \mathrm{kg}$ BM per d).

BMI ranged from 13.4 to 32.9 (average 20.7 ) $\mathrm{kg} / \mathrm{m}^{2}$ and chronic energy deficiency was implicated in $29 \%$ of the subjects. Subjects exhibiting clinical signs of arsenicosis had a $9 \%$ lower BMI than those without signs $(P=0.013$, df 82$)$. It may be concluded that malnourished individuals are more susceptible to arsenic toxicity. Furthermore, there was a weak negative correlation between daily arsenic intake from drinking water and BMI $(P=0.08$, df 95$)$. An earlier study has suggested that biochemical or behavioural changes may explain the observed lowering of nutritional status with arsenic intake ${ }^{(2)}$. In conclusion, the consumption of arsenic from drinking water and food often exceeded tolerable levels in Nawalpasi, with a significant relationship to arsenicosis prevalence observed, most notably amongst malnourished individuals. Further research is needed to understand the aetiology of arsenic toxicity in relation to nutritional status and other confounding factors. Thresholds for arsenic exposure should then be reviewed for suitability.

The cooperation of Filters for Families and financial support from the University of Leeds, The Charity of Harvey and Elizabeth Eakins and Edmond Arnold Educational Foundation is gratefully acknowledged.

1. National Arsenic Steering Committee (2007) The State of Arsenic in Nepal - 2005. Kathmandu, Nepal: UNICEF.

2. Maharjan M, Wantanabe C, Akhtar Ahmad SK et al. (2007) J Epidemiol Community Health 61, 389-394. 